\title{
Estratégias de coleta de dados com trabalhadores de baixa escolaridade
}

\author{
Livia de Oliveira Borges \\ José Q. Pinheiro \\ Universidade Federal do Rio Grande do Norte
}

\begin{abstract}
Resumo
Um olhar para as pesquisas desenvolvidas no campo da Psicologia Organizacional e do Trabalho no Brasil aponta que os pesquisadores optam por estudar categorias ocupacionais cujos trabalhadores são mais instruídos. Tal realidade minimiza as possibilidades de generalização e de aplicação dos resultados. Alguns pesquisadores, entretanto, insistem em focalizar as categorias mais desfavorecidas e concentradoras de pessoas com baixa escolaridade. Que opções metodológicas realizam? Quais instrumentos usam? Com o objetivo de trazer respostas a estas questões, foram levantadas as técnicas de coleta de dados utilizadas pelos pesquisadores. O uso de questionário estruturado é viabilizado como técnica de coleta de dados, na qual se recorre ao uso de gradações de tonalidades de cores em substituição às escalas tradicionais. Por fim, apresenta-se uma proposta baseada na combinação de técnicas. A divulgação da proposta pode contribuir para enfrentar o desafio da relevância social e da generalização dos resultados das pesquisas.
\end{abstract}

Palavras-chave: Baixa escolaridade, Analfabetos, Metodologia, Coleta de dados, Questionário

\begin{abstract}
Strategies of data collection with workers of low instructional level. The examination of the studies developed in the field of Organizational and Work Psychology in Brazil shows that researchers choose to study occupational categories whose workers are relatively well educated. This reality diminishes the possibilities of generalization and application of the results to other levels of instruction. Some researchers, however, persist in paying attention to categories of analysis in which they have many participants with low instructional level. In such a case, what are their methodological options? What instruments do they use? Trying to answer these questions, we identified the data collection technique used by the researchers. The use of the structured questionnaire becomes viable by means of color gradations, which replaces the traditional scales of numbers. At the end, a proposal based on a combination of techniques is presented. The present communication may contribute to facing the challenges of social relevance and generalization of research results.
\end{abstract}

Key words: Analphabets, Methodology, Data collection, Questionnaire

A s recentes transformações no mundo do trabalho, ao lado de problemas sociais como elevados índices de desemprego, instabilidade no emprego, dificuldades de acompanhamento do ritmo de mudanças tecnológicas, novas demandas de qualificação e dificuldades de organização dos trabalhadores, têm posto em pauta temáticas eminentemente psicossociais como cultura organizacional, significados atribuídos ao trabalho, compro- metimento organizacional e profissional, desenvolvimento de competências, processo de mudança e aprendizagem nas organizações, além da articulação entre trabalho e saúde. Tal realidade cria espaço de oportunidades para o incremento da produção científica no campo da Psicologia Organizacional e do Trabalho.

Estudiosos (por exemplo, Álvaro-Estramiana, 1995; Garrido, 1996; Katzell, 1994; Triandis, 1994), por conse- 
qüência, têm assinalado as mudanças já ocorridas, ou em curso, neste campo de conhecimento. Ao lado da tendência fortemente empírica dos tempos recentes, identificam a sofisticação crescente das técnicas de análise empregadas, a maior frequiência com que se combinam técnicas de coleta e de análise de dados, bem como as tendências a uma ampliação do alcance dos estudos, na proporção que têm abandonado a mera descrição de um fenômeno para estudar relações entre os mesmos, o que por sua vez implica na possibilidade de uma passagem de um nível micro de análise do comportamento para níveis cada vez mais macroscópicos. Pontuam ainda a tendência a uma maior consideração pelos aspectos sócio-históricos e situacionais na explicação dos comportamentos.

Tais tendências são inter-relacionadas, de forma que os avanços de alcance e de níveis de análise têm sido conquistados pela sofisticação e pelo pluralismo metodológico bem como pelo crescente rigor. Diversas publicações atestam o rigor em contar com questionários bem elaborados e confiáveis (por exemplo, García-Rodríguez, 1993; Gil-Monte \& Peiró, 1997; Jimenez, Rodríguez, Alvarez \& Caballero, 1997; Pasquali, 1999; Pasquali, Pinelli-Júnior \& Solha, 1994; Pasquali, Gouveia, Andriola, Miranda \& Ramos, 1994), na proporção em que se preocupam em identificar coeficientes de consistência, verificar validade, comparar consistência de questionários, avaliar a concatenação entre o que o questionário mede e o arcabouço teórico que o sustenta, entre outros aspectos.

A despeito disto, a Psicologia Organizacional e do Trabalho no Brasil continua reconhecidamente um campo de reduzido desenvolvimento científico, quando comparada à Psicologia como um todo. Os diferentes esforços dos pesquisadores brasileiros, quando estudam e discutem as questões de formação do Psicólogo Organizacional e do Trabalho, trazem respostas bastante elucidativas das razões pelas quais tal cenário tem persistido (Bastos \& Martins, 1990; Borges-Andrade, 1990; Iema, 1999; Zanelli, 1994; Zanelli, 1995). Entre estas, estão razões de naturezas muito diversas, como epistêmicas, de atribuição de importância, de subestimação de seu nível de complexidade, de fragmentação, de ausência de uma visão multidisciplinar, vacilações de identidade com o campo de estudo e referentes às posições ideológicas. Percebe-se, assim, que os desafios, tanto no seu conjunto como em cada tipo, são numerosos e bastante complexos.

Os desafios epistêmicos podem, por sua vez, ser problematizados partindo da observação da diversidade de populações a quem os conhecimentos e técnicas produzidas pela Psicologia Organizacional e do Trabalho se dirigem. A diversidade populacional pode ser caracterizada por diversos aspectos como nível instrucional, diferenças culturais, natureza das ocupações, entre outros. Tomando, então, como ponto de partida as diferenças de acesso à instrução formal no país e com o intuito de contribuir para a discussão desta temática (desafios epistêmicos oriundos da diversidade populacional), o presente artigo se detém nos seguintes problemas:

Qual a principal estratégia utilizada para enfrentar a diversidade de níveis de instrução dos participantes dos estudos?

Quais as implicações do uso da estratégia predominante?

É preciso coletar dados com trabalhadores de baixa instrução? Por quê?

Que alternativas técnicas tem se utilizado para superar tais problemas?

É possível utilizar questionários estruturados com trabalhadores de baixa instrução? Para quê?

$\mathrm{Na}$ busca de respostas a cada um destes problemas, nas demais seções deste artigo, avançar-se-á gradualmente na discussão temática, confrontando as definições populacionais e amostrais das pesquisas publicadas no campo da Psicologia Organizacional e do Trabalho com os princípios que os metodólogos têm defendido e com a experiência em pesquisar com trabalhadores de baixa instrução.

\section{Populações focalizadas nos estudos de Psicologia Organizacional e do Trabalho}

Fez-se uma incursão pela produção de Psicologia Organizacional e do Trabalho com a finalidade de entender como os pesquisadores desta área estão concretamente realizando suas opções metodológicas referentes às técnicas de coleta de dados, frente ao desafio de parte da PEA (População Economicamente Ativa) ter baixo nível instrucional ou serem analfabetos.

Para tanto, levantaram-se os artigos relatando pesquisas de campo ${ }^{1}$ que podem ser identificados como do campo da Psicologia Organizacional e do Trabalho, nas quatro revistas especializadas em Psicologia melhor avaliadas pela Comissão CAPES ${ }^{2} /$ ANPEPP $^{3}$, a saber: Psicologia USP; Psicologia: Reflexão e Crítica; Psicologia: Teoria e Pesquisa; e Estudos de Psicologia (Yamamoto et al., 1999). Examinaram-se os volumes/números, seguindo-se até o último número efetivamente publicado, no período de 1996 a 1999.

Como se sabe que os artigos em Psicologia Organizacional e do Trabalho não são encaminhados exclusivamente para revistas de Psicologia, levantaram-se também aqueles artigos publicados em uma revista de Administração, nos quais pelo menos um dos autores fosse psicólogo ou, vinculado a programa de pós-graduação de Psicologia. Este critério referente à formação do pesquisador foi preferido a um critério temático, porque o campo da Psico- 
logia Organizacional e do Trabalho é uma área claramente de interseção com a administração, motivo porque, ao se tentar usar critérios temáticos, tornam-se extremamente duvidosas as classificações realizadas. Certamente, um administrador selecionaria as mesmas pesquisas como de Administração de Recursos Humanos. Neste campo, escolhemos a Revista de Administração Contemporânea (RAC), por ser uma publicação da ANPAD (Associação Nacional em PósGraduação em Administração).

Na Tabela 1, como se vê, contaram-se o número de artigos por revista, a técnica utilizada para a coleta de dados (entrevistas, questionários e ambos) e quantos incluíam, nas amostras, indivíduos com baixa instrução (até a $4^{\underline{a}}$ série do Ensino Fundamental) ou contavam com amostras formadas por participantes a partir do Ensino Médio. Em referência ao nível de instrução, é importante esclarecer que apenas 7 (sete) artigos explicitavam o nível de instrução dos participantes da amostra. Nos demais, inferiu-se o nível instrucional baseado na caracterização da categoria ocupacional dos participantes e nos próprios procedimentos de coleta de dados relatados. Sobre tal classificação, assinala-se ainda que cabia uma classe intermediária entre as duas da tabela. No entanto, nenhum estudo foi encontrado que pudesse ser nela classificado.

Observou-se que, dos 15 (quinze) artigos, 5 (cinco) são relatos de estudos empíricos que incluem em suas amostras trabalhadores de baixa escolaridade, o que representa um terço dos estudos. E antes que o leitor otimista logo se anime, pensando que um terço não é uma parcela tão pequena, abrimos um parêntese para avisar que destes 5 (cinco), 3 (três) são da primeira autora do presente texto e todos os 5 (cinco) têm, como autores, professores/pesquisadores vinculados a duas universidades nordestinas $\left(\mathrm{UFRN}^{4} \mathrm{e} \mathrm{UFPB}^{5}\right)$.

Fechado o parêntese, inicia-se a análise pelos 10 artigos que tomam como amostra indivíduos com instrução a partir do ensino médio. De todos, em apenas um fica claro que toma executivos como sua população-alvo, em decorrência do próprio objetivo e da temática do estudo desenvolvido. Nos demais, os relatos conduzem a acreditar que é o procedimento de coleta de dados adotado que exclui empregados/trabalhadores de baixa escolaridade.

Chama atenção um artigo cujos autores se identificam com abordagem teórica em que predominam estudos com categorias ocupacionais de baixa qualificação em outros países, apesar de eles próprios terem elegido trabalhar com categorias mais qualificadas. É provável que tal opção tenha seguido motivações e curiosidades intelectuais dos pesquisadores, o que seria justificável. Entretanto, se são consideradas as características de nossa PEA e há preocupação com a relevância social e aplicabilidade do que se faz, é de se esperar opções dos pesquisadores nacionais e dos estrangeiros diferentes quanto ao grau de instrução das amostras estudadas.

É necessário compreender, contudo, que nos países centrais do capitalismo, quando se estudam categorias de "baixa qualificação", a adjetivação se dirige à natureza dos postos de trabalho e ao nível de exigência instrucional originada na organização do próprio trabalho. Tal fato não implica ne-

Tabela 1.

Artigos de Psicologia Organizacional e do Trabalho

\begin{tabular}{|c|c|c|c|c|c|c|}
\hline \multirow[b]{2}{*}{ Revistas } & \multicolumn{4}{|c|}{$\begin{array}{l}\text { Técnica de coleta de } \\
\text { dados/instrumento }\end{array}$} & \multicolumn{2}{|c|}{$\begin{array}{c}\text { Instrução da } \\
\text { amostra }\end{array}$} \\
\hline & $A$ & $B$ & $C$ & $D$ & $E$ & $F$ \\
\hline \multicolumn{7}{|c|}{ No campo da Psicologia } \\
\hline Psicologia: Teoria e Pesquisa & 5 & 2 & 3 & - & 1 & 4 \\
\hline Estudos de Psicologia (Natal) & 3 & 2 & - & 1 & 3 & 1 \\
\hline Psicologia USP & 1 & - & 1 & - & - & 1 \\
\hline Psicologia: Reflexão e Crítica & 1 & 1 & - & - & 1 & - \\
\hline Totais & 10 & 5 & 4 & 1 & 5 & 5 \\
\hline \multicolumn{7}{|c|}{ No campo da Administração } \\
\hline Revista de Administração Contemporânea (RAC) & 5 & - & 2 & 3 & - & 5 \\
\hline
\end{tabular}

Legenda:

$\boldsymbol{A}=$ Número de artigos; $\boldsymbol{B}=$ Entrevista; $\boldsymbol{C}=$ Questionário; $\boldsymbol{D}=$ Ambos; $\boldsymbol{E}=$ Incluindo baixa instrução; $\boldsymbol{F}=$ A partir do ensino médio 
cessariamente que os ocupantes dos postos apresentem baixa instrução. No Brasil, tal implicação se torna realidade. Desta forma, se os referidos pesquisadores tivessem a intenção de seguir a tendência dos estudos empíricos fundamentados na abordagem teórica que abraçavam, não poderiam aplicar os mesmos procedimentos de coleta de dados.

Assim, a principal estratégia para enfrentar o desafio da baixa escolaridade tem sido evitar coletar dados em tais camadas da população. Tal estratégia traz sem dúvida prejuízos metodológicos, além dos prejuízos relativos à relevância social das pesquisas. Assinala-se que Günther (1999), em artigo dedicado a orientar o pesquisador a elaborar questionário para uso em pesquisas de campo (ou survey), descreve a interdependência entre objetivos de uma pesquisa e a relação conceito/item e a relação população/amostra. A estratégia de evitação, já referida, rompe a interdependência descrita pelo metodólogo. Constitui-se, portanto, em uma variável interveniente: as limitações impostas pelas características dos questionários nas formas de aplicação e na seleção ou definição amostral. O rompimento da interdependência ocorre em dois pontos: na relação entre objetivo e população/amostra e no seio desta última relação (população/amostra). Comprometem-se, portanto, as possibilidades de generalizações.

Apesar de tal estratégia aplicada nos estudos, implícita ou explícita nos artigos, caracterizar-se pela fuga ao problema e não em lidar com ele diretamente, certamente é uma opção que guarda suas vantagens. Utilizar um instrumento e práticas de pesquisa desenvolvidas tendo em vista níveis elevados de instrução, sem adaptá-los às camadas de diferentes níveis de instrução, provavelmente geraria maiores prejuízos.

Da mesma forma, ignorar as camadas populacionais excluídas também pode involuntariamente conduzir o pesquisador a conclusões equivocadas. Este tipo de problema pode ser muito bem ilustrado, reportando-se à dissertação de Soares (1992). A despeito das qualidades de tal dissertação, o que interessa aqui é tratar dos limites que foram impostos ao trabalho empírico devido à importação do modelo da equipe MOW (1987). O estudo de Soares tinha como um dos objetivos estudar a variabilidade do significado do trabalho por ocupações. Utilizando os mesmos instrumentos da equipe MOW, que se dirigia a um público de instrução relativamente elevada, Soares só pode estudar categorias ocupacionais nas quais as pessoas apresentassem no mínimo $2^{\underline{0}}$ grau. Curiosamente, a autora encontra pouca variação entre as categorias ocupacionais, as quais estavam exatamente entre a única categoria de nível médio alvo do seu estudo e as 6 (seis) outras de nível superior. Ao leitor atento, fica a dúvida: caso contasse com categorias ocupacionais que se diferenciassem mais em nível de instrução, não en- contraria relação mais estreita entre significado do trabalho e categoria ocupacional?

Portanto, conclui-se desta análise que a estratégia de evitação do problema e/ou a opção de não estudar segmentos da PEA de baixa-instrução têm predominado nos estudos da Psicologia Organizacional e do Trabalho. Tal estratégia tem implicações epistêmicas na medida em que é fonte de rompimento dos vínculos entre o objetivo de estudo e as definições populacionais e/ou amostrais.

\section{Por que coletar dados com trabalhadores de baixa instrução?}

Compete agora perguntar: existem dificuldades em coletar dados entre pessoas com baixa instrução? Se sim, têm realmente impacto na produção do conhecimento na área de Psicologia Organizacional e do Trabalho? Por quê?

A mínima caracterização sócio-econômica do mundo do trabalho no Brasil demonstra que este se diferencia quanto ao nível de instrução de seus trabalhadores. Há analfabetos absolutos (pessoas que nunca tiveram acesso ao estudo), analfabetos funcionais (pessoas que estudaram, mas não dão conta de uma leitura), pouquíssimos (proporcionalmente) chegando ao ensino médio, muitos concluindo um ensino básico que não dá conta do que se espera neste nível.

Se simplesmente são traduzidos e aplicados questionários provenientes dos principais países produtores do saber, ou, aprende-se a entrevistar com eles, não serão coletados dados entre a parte da população de trabalhadores com baixa escolaridade. Escala de Likert, por exemplo, parece simples, mas qualquer pesquisador que a utilizou em sua forma tradicional medindo valores, significado do trabalho, comprometimento organizacional, ou variável semelhante, entre indivíduos com apenas ensino básico, irá recordar facilmente das dificuldades encontradas. Termina-se por anular muitos questionários, ou tendo uma aplicação muito mais exigente em cuidados, na qual o aplicador tem de assistir detalhada e demoradamente a cada participante.

Algumas outras modalidades de estruturação de questões, distintas das escalas de Likert, são ainda mais difíceis de serem utilizadas adequadamente por pessoas de baixa instrução e/ou analfabetos. Um exemplo é a questão de centralidade do trabalho, bastante utilizada nos estudos de significado do trabalho, a partir da publicação da pesquisa da equipe MOW (1987), que solicita, ao respondente, atribuir pontos a cada esfera de vida (trabalho, lazer, família, religião e comunidade) de forma que a soma dos pontos seja igual a cem. A estruturação desta questão é flexível porque permite revelar a hierarquia de importância relativa atribuída às diferentes esferas de vida e, ao mesmo tempo, que o respondente, caso lhe convenha, indique que duas esferas de vida estão num mesmo patamar. Permite também dife- 
renciar indivíduos que atribuem a mesma ordem de importância às esferas de vida, mas que atribuem distintas distâncias entre cada nível de importância. Em suma, permite hierarquizar e graduar.

Entretanto, mesmo entre níveis mais elevados de instrução, chega a ocorrer a repetição de alguns enganos por parte dos respondentes. Quando se utiliza tal estrutura de pergunta, encontram-se algumas respostas em que a soma excede a 100 e outras, em que não chega ao total. Mesmo utilizando o questionário de uma forma na qual se aplica questão a questão ao participante, é extremamente difícil, senão impossível, fazer o participante apresentar uma resposta autenticamente sua.

Por outro lado, exigir tais atitudes e comportamentos por parte dos aplicadores muitas vezes implica criar para os participantes de baixa escolaridade e/ou analfabetos condições muito diversas das oferecidas para os indivíduos mais instruídos, como por exemplo, anonimato e preenchimento do questionário mais independente do aplicador.

Poder-se-ia contra-argumentar: e para que coletar dados com tais segmentos da população, se eles já são minoria e os analfabetos estão gradualmente sendo erradicados? No censo de 1980 (Instituto Brasileiro de Geografia e Estatística [IBGE], 1980), a População Economicamente Ativa (PEA) estava composta de $27,2 \%$ de analfabetos ${ }^{6}$ e $72,7 \%$ de trabalhadores que estudaram no máximo 4 anos. No censo de $1991^{7}$ (IBGE, 1993 e 1994), tais números se reduzem: são $16,36 \%$ de analfabetos e 52,73\% que estudaram até 4 anos. Hoje, há mais crianças na escola, maior procura de vagas no ensino médio e no vestibular. Precisa-se aumentar as vagas no ensino médio e superior.

Dedutivamente, dedicar-se a preparar instrumentos de pesquisa para coletar dados entre os menos instruídos é, numa análise rápida, andar na contramão da história. Logo, não servirá para nada. Será que isto é suficiente para justificar fechar os olhos diante de uma parte imensa da realidade? Saber-se-á muito sobre uma parte da PEA e continuarse-á ingênuo diante da outra. Diante desta afirmação, compete formular nova questão: o que podemos conhecer junto a esta parte da PEA, excluída do sistema educacional, extinguir-se-á junto com o desaparecimento da condição de analfabetos e/ou de pouco instruídos? Recolocando tal questão, recorre-se a um exemplo: pesquisando-se sobre valores do trabalho, qual a garantia de que os valores destas camadas da população são os mesmos das demais? Ou que essas pessoas organizam tais valores da mesma forma? Estas possíveis formas e conceitos necessariamente desaparecerão quando conseguirem acesso à instrução? Pouco provável.

É argumento amplamente aceito na Psicologia Social que valores são historicamente produzidos. Instrução, certamente, é uma variável que contribui para a construção dos valores, mas não se aceitaria que seja o único elemento. Os condicionantes históricos são muitos. Assim, amparados no conhecimento disponível hoje sobre a construção dos valores, torna-se uma hipótese mais razoável prever que persistirão à elevação da instrução.

Desprezar das pesquisas todos os indivíduos de baixaescolaridade da PEA tem ainda efeito mais forte, se considerado que não estão distribuídos aleatória e proporcionalmente em todas as categorias ocupacionais. Há concentração de baixa escolaridade e analfabetismo entre, por exemplo, operários da construção civil ${ }^{8}$, trabalhadores da agricultura, empregados no setor de higiene e limpeza, entre outras categorias ocupacionais.

Da mesma forma que é fácil entender que a variável instrução não é independente da categoria ocupacional, é possível entender que também não é independente de outras, entre as quais a renda e a classe sócio-econômica. Reconhecendo tais ausências de independência, pode-se também compreender que deixar de incluir, nas amostras de pesquisa, indivíduos de baixa escolaridade, pode implicar deixar de estudar segmentos ocupacionais inteiros ou quase inteiros da PEA.

Tal ocorrência, do ponto de vista metodológico, tem implicações tanto qualitativas como quantitativas. Ora deixamos de identificar e diferenciar atributos de um determinado objeto de estudo, ora negligenciamos parte da variância de outros atributos. Metodólogos, como Pasquali (1999), consideram ambos os passos — (1) identificar, diferenciar e conceituar atributos, (2) tendo a consciência que são estes que podem ser mensurados e não o próprio objeto - momentos importantes, necessários e interdependentes no processo de tentar aprofundar-se sobre um objeto de estudo.

Considerando estes últimos aspectos (especificidades do segmento de baixa escolaridade na PEA, não-independência da variável instrução em relação a outras, como categoria ocupacional, renda e classe sócio-econômica), a questão a ser levantada é outra: em um período histórico, em que a corrida pelo conhecimento e pela produção de tecnologias está entre as maiores batalhas e desafios, deve-se aguardar vencer primeiro a batalha pela qualificação e acesso democrático ao estudo, para só depois ousar conhecer um largo segmento da PEA? Uma resposta positiva a esta questão significaria optar por continuar marchando cada vez mais distante dos países desenvolvidos na produção de conhecimento.

Em suma, entende-se que é preciso desenvolver pesquisas coletando dados com segmentos de baixa instrução para poder dar conta de uma diversidade maior de aspectos dos constructos estudados no campo da Psicologia Organizacional e do Trabalho e ampliar o espectro de categorias ocupacionais atingidas. Principalmente o segundo motivo tem implicações políticas e de relevância social, porém 
tem também implicações epistêmicas no que se refere às possibilidades de generalização dos resultados dos estudos.

Além disto, percebemos que a dissimulação da falta de instrumentos adequados através da adaptação improvisada da forma de aplicação cria situações diferenciadas de anonimato e autonomia no preenchimento de questionários, tendo implicações éticas. É por todas as razões aqui expostas que se defende a necessidade de se construir instrumentos de pesquisa aplicáveis a indivíduos com baixo nível de escolaridade e a analfabetos. E este desafio é terceiro mundista, porque os países centrais, produtores hoje da maior parte do conhecimento e da tecnologia, não serão os que o abraçarão. Para tais países, o desafio de ter pessoas analfabetas e/ou de baixa escolaridade não está posto. Não é dificuldade metodológica para os pesquisadores daqueles países.

\section{$A$ alternativa da entrevista}

Compete agora explorar as estratégias metodológicas utilizadas naqueles estudos que incluem trabalhadores de baixa escolaridade. Destes, importa começar tratando sobre a adoção da entrevista como principal meio de coleta de dados. Albuquerque, Lobo e Raymundo (1999), em estudo que tem como população/amostra alvo trabalhadores da área rural, demarcam as sutilezas diferenciadoras nos cuidados adotados para abordar os possíveis participantes de sua amostra, obtendo a adesão dos mesmos à participação.

Albuquerque (2000) chama a atenção para a importância em considerar variáveis ambientais na determinação da formulação e expressão do comportamento. Descreve, então, diversas particularidades do homem rural, que vão desde o tempo (mais extenso) e táticas diferenciadas para estabelecimento do rapport a formas de apresentação e chama atenção para o fato de que, quando se trata de casais, se deve abordar primeiro os homens. Para delinear seus procedimentos de coleta de dados, recorre a desde informações demográficas até ao conhecimento que só é possível adquirir no contato com estes segmentos da população. Com as táticas adotadas, consegue revelar aspectos psicossociais que nenhum instrumento previamente importado de outros países seria capaz de identificar, como um aumento de status do homem rural pela oportunidade do recebimento do benefício da aposentadoria. Imaginem se utilizasse um instrumento, seja um roteiro de entrevista ou um questionário estruturado, que partisse do suposto de que o aposentado perde seu status e a identificação profissional, apresentando perdas a serem elaboradas. Que resultados poderiam ser esperados?

Esse exemplo traz, portanto, a lição de ser necessário mergulhar na categoria ocupacional a fim de ser capaz de desenvolver uma relação empática. É preciso, por exemplo, não tentar se fazer de igual, mas saber compreender e respeitar seus hábitos diferenciados, inclusive as particularida- des da linguagem. Aliás, para este aspecto da linguagem a literatura técnica sobre elaboração de questionário vem chamando a atenção, como, por exemplo, faz Pasquali (1999, p. 49): "o linguajar típico da população alvo deve ser utilizado na formulação dos itens."

Um segundo artigo (Veloso, 1996) também relata estudo empírico com trabalhadores rurais, embora se detenha menos nos aspectos metodológicos. Mesmo assim, chama atenção o fato de que o enfronhamento da autora na realidade em que estão inseridos os participantes de sua amostra se revela ao longo do artigo. Trata, inclusive, de uma modalidade de vínculo de trabalho (trabalho alugado) que certamente não se encontrará nem na área urbana nem na literatura internacional.

Um terceiro estudo (Borges, 1996) é desenvolvido com operários da construção civil, comerciários e costureiras de pequenas fábricas de confecções. Tal estudo está marcado por revelar categorias do significado do trabalho diferenciadas daquelas consideradas nos grandes estudos internacionais e nos nacionais que derivaram dos modelos dos primeiros. Não que os estudos internacionais não apresentassem excelente qualidade, mas sim porque existem categorias imbricadas apenas na realidade brasileira. Por exemplo, encontrar a referência a perceber o trabalho como uma expressão da saúde corporal só é possível num contexto não só de trabalho braçal, mas no qual não há amparo social para os enfermos. Adoecer, para estas pessoas, significa não-trabalhar e não terem como se auto-sustentar. Assim é que trabalhar é prova de saúde e vice-versa.

Tanto o primeiro estudo quanto o terceiro expõem claramente sua condição de exploratórios, considerando que devem ser seguidos de estudos mais estruturados que aproveitem as categorias encontradas.

Um pouco mais além, o terceiro aplica técnicas estatísticas de forma exploratória. Examina as distribuições de freqüência dos diversos atributos do trabalho encontrados, constatando que três deles - sobrevivência, exploração e realização - eram mais freqüentes. Devido a isto tomou tais atributos como o núcleo da representação social do trabalho. As entrevistas haviam sido conduzidas, perguntado-se pelo significado do trabalho, mas sem fornecer nenhum atributo ao entrevistado. A estratégia utilizada na entrevista foi útil para levantar atributos distintos daqueles relatados na literatura consultada, como já se exemplificou, e também para afirmar que os três atributos citados são os que os entrevistados elucidam com mais facilidade. No entanto, não pode responder a perguntas como: para os entrevistados estes atributos apresentam o mesmo nível de importância? Outros atributos, observados no conteúdo das entrevistas com menor freqüência, caso fossem apresentados, não poderiam ser valorizados por maior número de entrevistados? 
O mesmo estudo também analisou distribuições de frequiências, cruzando-as duas a duas e estimando o Qui-Quadrado de cada dupla. Terminou por encontrar associações, as quais revelam conceitos peculiares e não hipotetizados inicialmente no estudo. Assim, por exemplo, são encontrados dois conceitos distintos de exploração. Um deles compartilhado pelos operários da construção civil que associam exploração à dureza do trabalho e outro, pelas costureiras que associam exploração à negação dos seus direitos. Tal exploração das relações quantitativas dos resultados é possível hoje recorrendo aos recursos da informática que permitem gerar tantos coeficientes e análises estatísticas quanto desejados e repeti-los de muitas formas, num tempo extremamente curto, se comparado ao tempo que se usaria desenvolvendo-os manualmente, mesmo que não consistissem em cálculos de elevada complexidade. Mesmo assim, não é possível ultrapassar análise de associações dois a dois. Muito interessante o que revelaram as diferentes associações com o atributo "exploração" nas diferentes categorias ocupacionais. No entanto, tais relações estão testadas apenas considerando a ocorrência, ou não, de cada atributo no discurso do trabalhador, e não níveis de importância de cada um, ou qualquer outra graduação.

Tudo isto exposto sobre o emprego da entrevista para coletar dados, sintetiza-se que ela é muito útil na exploração de atributos de um fenômeno ou objeto de estudo e para apropriação da linguagem do trabalhador alvo dos estudos, bem como para iniciar a familiarização do pesquisador com contexto de trabalho e de vida dos participantes. Entretanto, como estratégia única impõe limites claros às possibilidades de análises quantitativas dos dados, porque o que é coletado é de natureza predominantemente categórica, o que implica na sua insuficiência para responder questões pautadas em relações mais complexas entre variáveis.

Em suma, considera-se que a entrevista é um meio de coleta de dados importante junto a trabalhadores de baixa instrução, principalmente no sentido de explorar novos atributos dos constructos, deficiência apontada anteriormente neste artigo. Entretanto, não pode ser tomado como único, sob o risco de andar-se na contra-mão das tendências gerais do campo de estudo referidas na introdução deste artigo, como o pluralismo metodológico, crescente rigor, avanços de alcance e de articulação de níveis de análise.

$\mathrm{Na}$ análise do uso da entrevista emerge também um outro aspecto de cunho epistemológico: a entrevista foi útil na revelação de novos aspectos, sendo adotada junto com uma perspectiva contextuante de análise dos resultados.

\section{Aplicando questionários estruturados em trabalhadores de baixa escolaridade}

Os limites apontados na seção anterior são bastante conhecidos por quem se dedica a estudar aspectos metodoló- gicos e/ou à psicometria. É fácil reconhecer que se há aperfeiçoado na elaboração de escalas, bem como na exploração e avaliação da validade e da confiabilidade das mesmas. E ao introduzir-se este artigo, comentou-se que avanços têm sido conquistados no campo da Psicologia Organizacional e do Trabalho através do pluralismo, sofisticação e rigor metodológico.

Para muitos estudiosos (por exemplo, Madill, Jordan \& Shirley, 2000; Smith, 1994), falar em pluralismo remonta sempre a críticas de se tentar juntar o que é inconciliável ou a uma visão carente em sustentação epistemológica. No entanto, há publicações que oferecem apoio e fundamento para tanto. Assim, Yakhot (1975), expondo sobre o materialismo dialético, argumenta que qualidade e quantidade se transformam uma na outra, não só através do salto qualitativo, mas porque ambas são atributos interdependentes do mesmo objeto. Triandis (1994) percebe as análises qualitativas e quantitativas como interdependentes, consistindo em momentos distintos do mesmo processo. Advoga a conjugação das técnicas de análise para apoiar o avanço dos estudos. Katzell (1994) e Álvaro-Estramiana (1995) percebem como uma das grandes tendências na Psicologia Social a combinação de técnicas de coleta e análise de dados. Na literatura nacional, brilha o artigo de Fernandes (1997), que discorre meticulosamente sobre os conceitos de qualidade e quantidade. Para o autor referido, "a qualidade é, de fato, a idéia com que elaboramos a idéia de 'conceito' e, em Lógica, ou em Matemática, a idéia de 'propriedade'.” (Fernandes, 1997, p. 17).

Sobre a interdependência entre qualidade e quantidade o referido autor também afirma: "A noção de quantidade pressupõe (sem sabermos o que é realmente!) a noção de qualidade: quantidade é, em última análise, a repetição de uma qualidade." (Fernandes, 1997, p.17). E, mais adiante, acrescenta: "Se considerarmos qualidades 'incomparáveis', jamais poderíamos 'contar', p. ex., círculos, quadrados ... e triângulos, como membros da extensão do conjunto, por exemplo, de figuras geométricas." (Fernandes, 1997, p.18).

A interdependência entre análises qualitativas e quantitativas e entre aplicação de questionário e realização de entrevista revela-se na bibliografia sobre a elaboração de escalas e/ou questionários (e.g., Pasquali, 1999; Günther, 1999). Cada passo — identificar atributos, relacionar conceitos/atributos aos itens dos questionários, estudar a variabilidade de determinados atributos - exige, ora entrevista, ora teste direto do questionário; ora fina análise qualitativa, ora aplicação de técnicas estatísticas simples e/ou sofisticadas. O sucesso de cada passo depende do outro.

Expor todos estes pensamentos sobre a relação dialética entre qualitativo e quantitativo, não significa acreditar que tal discussão está superada definitivamente. Mesmo na lite- 
ratura internacional, há autoras como Madill, Jordan e Shirley (2000) que, partindo do reconhecimento da existência de uma diversidade de paradigmas, argumentam que os mesmos critérios de análises, conduzindo a identificar implicações distintas em cada abordagem, são também distintos. A intenção delas é mostrar que, por exemplo, objetividade e confiabilidade não se aplicam a estudos qualitativos, mas apenas aos quantitativos, porque se fundamentam numa referência do realismo científico ou ingênuo.

Na literatura nacional, Smith (1994) divide todos pesquisadores apenas em positivistas e idealistas. Associa as técnicas qualitativas ao idealismo e as quantitativas ao positivismo. Baseado nesta divisão, considera que combinar as duas técnicas não encontra fundamento.

Contrariamente a Smith (1994), compreende-se que pressupostos positivistas (que ele tanto rejeita) podem estar por trás ou fundamentando uma "análise qualitativa". Nesta direção, Patto (1997), discutindo a psicometria na Psicologia Educacional, critica "o psicologismo" que pressupõe identificar todas as causas de dificuldades de aprendizagem e adaptação escolar nos distúrbios psíquicos e físicos.

Diante da aceitação da interdependência dos aspectos quantitativos e qualitativos de um objeto ou de um fenômeno, o leitor certamente se deu conta que, quando se discutia na seção anterior o emprego da entrevista como estratégia única de coleta de dados, trazia-se uma combinação dos dois modos de análise (qualitativo e quantitativo). Identificar a categoria (por exemplo, atributos de um fenômeno) e conceituá-la é o momento da qualidade, contar a categoria (freqüência de ocorrência do atributo, por exemplo), analisar as distribuições de freqüência e aplicar Qui-quadrado são momentos da análise quantitativa. E são momentos interdependentes, posto que foi exemplificado que a independência entre dois atributos rejeitada pela aplicação do Qui-quadrado (análise quantitativa), elucidou a variação conceptual do atributo (análise qualitativa).

Por fim, compreendida a relação de interdependência entre aspectos qualitativos e quantitativos, não se vê como considerar os fenômenos psíquicos complexos, multifacetados e multideterminados, advogando que se deve usar uma única técnica de coleta de dados. A questão a ser posta é, então: como aplicar este mesmo caminho para os estudos com trabalhadores de baixa instrução?

Borges $(1997,1999)$ e Borges \& Tamayo (2000) relatam estudos que incluem analfabetos e indivíduos de baixa escolaridade na amostra, tendo como categorias ocupacionais focalizadas os operários da construção habitacional e os comerciários de redes de supermercado. Referem-se à construção e uso de questionário estruturado sobre o significado do trabalho. Tal questionário foi construído de forma que seus itens refletissem as categorias que a bibliografia inter- nacional e nacional sobre o assunto sugeriam, mas também as categorias levantadas naquele terceiro estudo que tinha na entrevista a principal técnica (Borges, 1996). Além dos itens fundamentarem-se nas categorias encontradas, aproveitou-se a linguagem revelada nas entrevistas daquele estudo. Assim, há frases como "trabalhar é pegar no pesado, é fazer força e trabalhando, garanto meu sustento". Os referidos artigos revelam estruturas fatoriais que refletem os significados atribuídos ao trabalho pelos empregados de categorias ocupacionais específicas e que trazem as marcas da realidade local (brasiliense e natalense). Seus fatores só puderam, por sua vez, ser apropriadamente interpretados porque o estudo relatado combinava aplicação de questionários com entrevistas. O sentido da articulação dos itens que compunham cada fator torna-se claro através do desenvolvimento de um trabalho de interpretação, que incluía um movimento de ir e vir entre os resultados da análise fatorial e o conteúdo das entrevistas. Nenhuma técnica de coleta de dados em separado permitiria a mesma compreensão dos resultados daquele estudo.

Mas, cabe agora questionar: que procedimentos foram adotados para estruturar o questionário e aplicá-lo em número amplo de trabalhadores viabilizando a aplicação da análise fatorial? Como aplicar um questionário estruturado em analfabetos e/ou ou indivíduos com baixa escolaridade, garantindo condições, tais como o participante responder por si, anonimato e aplicação coletiva? Tratou-se destes problemas gradualmente, pensando em alternativas, eliminado umas, complementando com outras, até que se contou com duas versões distintas de responder e aplicar o questionário.

Assim, registra-se que, para cada item, os participantes da amostra apresentam duas respostas: uma sobre a realidade (atributos descritivos) e outra baseada na definição de "deve ser" dos mesmos (atributos valorativos). As respostas consistem em designar pontos de 0 a 4 . Refletia-se aqui o que Günther (1999) descreve sobre a interdependência entre os objetivos e a relação conceito/item. Portanto, se o modelo conceitual hipotético previa dois tipos de atributos (valorativos e descritivos), o questionário suscitava respostas em um plano e no outro.

Na primeira versão, aplicável a trabalhadores sem instrução formal ou que cursaram até a quarta série do ensino fundamental, lança-se mão de recursos não-verbais. Deste modo, os participantes apresentam suas respostas utilizando cartões de duas cores básicas — verde e azul — uma cor para cada resposta, e com graduação de tonalidade em substituição aos pontos. A cor verde foi utilizada para as respostas correspondentes aos atributos valorativos e a cor azul, para as respostas correspondentes aos atributos descritivos. Estas cores foram usadas considerando seu significado simbólico de esperança e racionalidade. Deste modo, quanto 
mais escuro o tom do cartão verde escolhido pelo participante, mais o conteúdo da frase trata de algo que ele considera que deve ser ou que é certo. E quanto mais escura a tonalidade do cartão azul escolhido, mais a frase descreve a realidade, ou o que é.

A cada participante (aplicação coletiva) era entregue uma caixa subdividida em compartimentos retangulares, nos quais os cartões estavam ordenados segundo as tonalidades. Os participantes escolhiam dois cartões - um azul, outro verde - a cada item lido pelo(a) aplicador(a).

Cartões escolhidos, o participante colocava-os em um envelope pequeno, previamente numerado conforme o item. Este envelope era, então, guardado em outro maior, o qual reunia todos os envelopes pequenos de um mesmo participante, sem identificá-lo.

A segunda versão, aplicável a partir do início da segunda parte do ensino fundamental (a partir da quinta série), foi preparada para ser respondida com o uso do lápis pelo próprio participante. Considerando, entretanto, que não se destinava a um nível de instrução elevado e a adequação de primar pela semelhança com a primeira versão, mesclaramse características verbais e não-verbais. Os participantes liam as frases e respondiam marcando círculos ou retângulos cheios. Os círculos substituem os cartões verdes e os retângulos substituem os cartões azuis. A graduação das escalas é representada pelos tamanhos crescentes dos círculos e dos retângulos. Analogamente à primeira versão, considerou-se aqui o simbolismo de objetos circulares e retangulares.

Desenvolveu-se também uma adaptação daquela questão sobre centralidade no trabalho, já referida anteriormente. Para tal passo, encomendaram-se desenhos que representassem cada esfera de vida. Testou-se a identificação dos desenhos junto a membros das categorias com as quais pretendíamos desenvolver o estudo. E na aplicação da questão, solicitava-se aos participantes que ordenassem os desenhos (cada um em um cartão) de acordo com a importância de cada esfera de vida.

Tanto o procedimento através dos cartões coloridos como aquele com os desenhos se mostraram úteis e confiáveis. Estas afirmações baseiam-se tanto no que se viu e se ouviu dos trabalhadores participantes nas sessões coletivas de aplicação, quanto nos tratamentos estatísticos aplicados. Entretanto, a adaptação da questão de centralidade do trabalho traz limitações, pois que minimiza sua flexibilidade assinalada anteriormente. Quem a responde, apenas hierarquiza as esferas de vida, mas não as gradua.

No início da aplicação dos questionários sentia-se que a equipe responsável receava dispor de uma alternativa inviável, excessivamente trabalhosa e de pouca compreensão para os trabalhadores. A experiência trouxe agradáveis surpresas. Primeiro, em contrapartida ao trabalho adicional que se tem aplicando um questionário tradicional com estas características, como preparar a equipe aplicadora e exercitar a paciência com cada trabalhador, encontrava-se a acessibilidade do trabalhador simples, que se orgulha de participar de uma pesquisa posta em desenvolvimento por uma universidade. Segundo, junto à acessibilidade e desejo de colaborar, revelam suas próprias formas de raciocinar. Assim, diante da explicação sobre o uso dos cartões por graduação de cores, surgiam do próprio grupo formas de facilitar a exposição. Por exemplo: operários da construção habitacional comparavam a gradação das cores (escala de Likert) a uma escada, na qual se sobe batente a batente; trabalhadores das redes de supermercados comparavam a mesma gradação de cores às prateleiras da loja.

Do ponto de vista estatístico, as estruturas fatoriais encontradas mostraram-se válidas na proporção da variância explicada e nos coeficientes Alfa de Cronbach estimados para cada conjunto de itens que compunham um fator. A interpretação dos fatores, entretanto, apoiou-se tanto nos itens componentes quanto nas entrevistas das quais haviam sido extraídos.

Esta experiência pode ser transferida para questionários medindo outros objetos e pode se constituir em incentivo para cada pesquisador desenvolver procedimentos adequados aos conceitos com os quais trabalha. É apenas uma saída encontrada entre muitas que a criatividade humana pode dar conta. No entanto, sua utilidade aqui é mostrar que é possível aplicar a sofisticação, pluralidade metodológica, rigor conceitual e de tratamento dos dados que demarcam as tendências epistemológicas das pesquisas em Psicologia Organizacional e do Trabalho nos estudos que têm em conta as particularidades da realidade local brasileira, coletando dados com segmentos dos trabalhadores cuja instrução é reduzida ou totalmente ausente. Realidade precária não justifica estudos precários por si.

Obviamente, tais procedimentos guardam muitas limitações. O uso dos cartões coloridos e em tonalidade graduadas em substituição ao formato numérico tradicional da Escala de Likert, por exemplo, implica num registro demorado e que precisa ser feito antes da reutilização do mesmo material. Exige, portanto, uma equipe com bastante tempo de dedicação ao trabalho. O material também é bastante volumoso para a condução, distante da praticidade de questionários em papel. A adaptação da questão de centralidade do trabalho através dos desenhos levou a perda da flexibilidade que esta questão tinha no primeiro formato. Portanto, há muito o que se aperfeiçoar.

Por fim, lembra-se que, da mesma forma que ocorre com outros segmentos populacionais, não é o uso de uma determinada técnica de coleta e de análise de dados que permite adotar uma perspectiva dialética-materilista que toma a necessidade de contextuar os dados coletados para poder 
compreendê-los de forma mais abrangente. Porém, o pluralismo do uso de técnicas vem ampliar o arsenal técnico para se atuar nesta mesma perspectiva, ampliando as possibilidades de se manter os vínculos entre objeto de estudo, definição populacional/amostral e análise dados.

\section{No lugar de concluir}

A prática de pesquisa no que se refere a lidar com trabalhadores/empregados de baixa escolaridade e analfabetos é, por tudo que foi exposto, demasiadamente escassa ou tipicamente iniciante. Por isso, não há o que concluir, mas apenas o que se tentar sistematizar.

O não desenvolvimento de habilidades e de técnicas para coletar dados, junto ao referido segmento de trabalhadores/ empregados, conduz a maioria dos estudos a ignorar tais camadas da PEA. A análise de uma pequena amostra de artigos do campo da Psicologia Organizacional e do Trabalho no Brasil mostra que a estratégia mais utilizada pelos pesquisadores, frente a tal desafio, é justamente ignorar os referidos indivíduos, o que gera problemas de ordem epistemológicas aos estudos: ora cerra-se na ignorância de atributos dos nossos objetos de estudo, ora, de parte da variância de outros atributos, ora ocorre um rompimento na relação entre as definições dos objetivos de estudo e da população/amostra.

Desenvolver habilidades para coletar dados com os referidos indivíduos é um desafio para pesquisadores brasileiros. Decorrente das características populacionais de cada país, tal problema metodológico não está posto nos países avançados.

A falta de habilidades para coletar dados com trabalhadores/empregados de baixa escolaridade não é, evidentemente, absoluta. Há também estudos que incluíam estes indivíduos em suas amostras, iniciando um aprendizado que permite esboçar uma proposta com algum amparo empírico, a qual se caracteriza sucintamente pelos seguintes pontos:

- Enfronhar-se e/ou aprofundar o conhecimento do contexto de cada categoria ocupacional e de seus segmentos formados pelos indivíduos de baixa-escolaridade;

- Não esquecer o caráter multi e interdisciplinar do campo de estudo;

- Apoiar-se no conhecimento do contexto para estabelecer caminhos peculiares de rapport, apresentações e adequação de instruções;

- Combinar técnicas de coleta de dados que permitam revelar novas qualidades (atributos) as quais são específicas destes segmentos da PEA;

- Viabilizar o uso de Escala de Likert, quando necessário, substituindo números por recursos não verbais como tonalidades ou tamanhos de figuras (geométricas), conforme exemplificado anteriormente;
- Usar desenhos como opção para substituir alternativas de respostas nominais;

- Responsabilizar-se por criar novas alternativas viáveis e congruentes com o contexto, no qual se planeja desenvolver cada pesquisa.

Em síntese, tenta-se aprender a coletar dados junto a trabalhadores/ empregados de baixa escolaridade e/ou analfabetos e chamar a atenção dos psicólogos organizacionais e do trabalho para a importância de desenvolver tal aprendizado principalmente gerando, testando e compartilhando o uso de técnicas adequadas. A riqueza metodológica, que caracteriza os estudos com outros segmentos populacionais, transferida para estudos com estes segmentos pode ter um impacto relevante na qualidade geral dos estudos.

\section{Referências}

Albuquerque, F. J. B. (2000, maio). Uma aproximação metodológica ao ambiente rural. Trabalho apresentado no VIII Simpósio Brasileiro de Pesquisa e Intercâmbio Científico - ANPEPP). Serra Negra, São Paulo.

Albuquerque, F. J. B., Lobo, A. L., \& Raymundo, J. S. (1999). Análise das repercussões psicossociais decorrentes da concessão de benefícios rurais. Psicologia: Reflexão e Crítica, 12(2), 503-519.

Álvaro-Estramiana, J. L. (1995). Notas finales acerca de las características y objeto de la Psicología Social. In J. L. Álvaro-Estramiana (Org.), Psicología Social: perspectivas teóricas y metodológicas (pp. 116123). Madrid: Siglo Veintiuno de España.

Bastos, A. V. B., \& Martins, A. H. C. G. (1990). O que pode fazer o psicólogo organizacional. Psicologia: Ciência e Profissão, (1), 10-18.

Borges-Andrade, J. E. (1990). Avaliação da profissão segundo os psicólogos da área organizacional. Psicologia: Ciência e Profissão, (1), 1923.

Borges, L. O. (1996). A representação social do trabalho. Estudos de Psicologia, 1, 7-25.

Borges, L. O. (1997). Os atributos do significado do trabalho e sua mensuração. Psicologia: Teoria e Pesquisa, 13(2), 211-220.

Borges, L. O. (1999). A estrutura fatorial dos atributos do trabalho. Estudos de Psicologia, 4, 107-139.

Borges, L. O., \& Tamayo, A. (2000). A estrutura cognitiva do significado do trabalho [Texto completo]. In Associação Nacional dos Programas de Pós-Graduação em Administração (Org.), $24^{\circ}$ ENANPAD - Encontro da Associação Nacional dos Programas de Pós-Graduação em Administração (Formato CD-ROM). Florianópolis: Autor.

Fernandes, S. L. C. (1997). Qualidade e quantidade em pesquisa psicológica. Cadernos de Psicologia, 1, 13-45.

García-Rodríguez, Y. (1993). Principales medidas en Psicología del Desempleo. In Y. García-Rodríguez (Org.), Desempleo: alteraciones psicológicas (pp. 55-94). Valencia: Promolibro.

Garrido, A. (1996). Psicología Social del Desempleo. In J. L. Álvaro, A. Garrido \& J. R. Torregrosa (Orgs.), Psicología Social Aplicada (pp. 122-154). Madrid: McGraw-Hill.

Gil-Monte, P., \& Peiró, J. M. (1997). Desgaste psíquico en el trabajo: el sindrome de quemarse. Madrid: Síntesis.

Günther, H. (1999). Como elaborar um questionário. In L. Pasquali (Org.), Instrumentos psicológicos: manual prático de elaboração (pp. 231258). Brasília: LabPAM; IBAPP.

Intituto Brasileiro de Geografia e Estatística [IBGE]. (1980). Censo Demográfico de 1980. Mão-de-Obra. Rio de Janeiro: Autor. 
Instituo Brasileiro de Geografia e Estatística [IBGE]. (1993). Censo Demográfico 1991: Indicadores Sócio-Demográficos. Grandes Regiões e Unidades da Federação. Rio de Janeiro: Autor.

Instituo Brasileiro de Geografia e Estatística [IBGE]. (1994). Mapa do Mercado de Trabalho no Brasil. Rio de Janeiro: Autor.

Iema, C. R. D. (1999). Um estudo teórico sobre a formação do psicólogo organizacional no Brasil. Psicologia: Teoria e Prática, 1(1), 31-41.

Jimenez, B. M., Rodríguez, R. B., Alvarez, A. M., \& Caballero, T. M. (1997). La evaluación del burnout. Problemas y alternativas. El CBB como evaluación de los elementos del proceso. Revista de Psicología del Trabajo y de las Organizaciones, 13(2), 185-207.

Katzell, R. (1994) Contemporary meta-trends in Industrial and Organizational Psychology. In H. C. Triandis, M. D. Dunnette \& L. M. Hough (Orgs.), Handbook of Industrial \& Organizacional Psychology (v. 4, pp. 1-94). Palo Alto, California: Consulting Psychology.

Madill, A., Jordan, A., \& Shirley, C. (2000). Objectivity and reability in qualitative analysis: Realist, contextualist and radical constructionist epistemologies. British Journal of Psychology, 91, 1-20.

MOW International Research Team (1987). The meaning of working. Londres: Academic Press.

Pasquali, L. (1999). Testes referentes a constructo: teoria e modelo de construção. In L. Pasquali (Org.), Instrumentos psicológicos: manual prático de elaboração (pp. 37-71). Brasília: LabPAM; IBAPP.

Pasquali, L., Pinelli-Júnior, B., \& Solha, A. C. (1994). Contribuição à validação e normatização da escala de ansiedade-traço do IDATE. Psicologia: Teoria e Pesquisa, 10(2), 411-420.

Pasquali, L., Gouveia, V. V., Andriola, W. B., Miranda, F. J., \& Ramos, A. L. M. (1994). Questionário de Saúde Geral de Goldberg (QSG): adaptação brasileira. Psicologia: Teoria e Pesquisa, 10(3), 421-438.
Patto, M. H. S. (1997). Para uma crítica da razão psicométrica. Psicologia USP, 8(1), 47-62.

Schwarcz, L. M. (1997). Dos males da medida. Psicologia USP, 8 (1), 33 45.

Smith, J. K. (1994). Pesquisa quantitativa versus qualitativa: uma tentativa de esclarecer a questão. Psico, 25(2), 33-51.

Soares, C. R. V. (1992). Significado do trabalho: um estudo comparativo de categorias ocupacionais. Dissertação de mestrado não-publicada, Universidade de Brasília. Brasília.

Triandis, H. C. (1994). Cross-cultural Industrial and Organizational Psychology. In H. C. Triandis, M. D. Dunnette \& L. M. Hough (Orgs.), Handbook of Industrial \& Organizacional Psychology (v. 4, pp. 103162). Palo Alto, California: Consulting Psychology.

Veloso, T. M. G. (1996). A representação social do trabalho: um estudo empírico com trabalhadores da construção civil, indústrias de confecções e costura e comércio em Brasília. Estudos de Psicologia, 1(1), 26-35.

Yakhot, O. (1975). O que é materialismo dialético? Lisboa: Estúdios Cor. Yamamoto, O. H., Koller, S. H., Guedes, M. C., LoBianco, A. C., Sá, C. P., Hutz, C. S., Bueno, J. L. O., Macedo, L., \& Menandro, P. R. M. (1999). Periódicos científicos em Psicologia: uma proposta de avaliação. Infocapes, 7(3), 7-13.

Zanelli, J. C. (1994). O psicólogo nas organizações de trabalho: formação e atividades profissionais. Florianópolis: Paralelo.

Zanelli, J. C. (1995) Formação profissional e atividades de trabalho dos psicólogos nas organizações. Psicologia: Teoria e Pesquisa, 11(1), $41-50$

\section{Notas}

1 O uso deste critério implica que foram excluídos deste levantamento artigos de revisão bibliográfica, de análise de documentos, de reflexão conceptual, análises epistemológicas e metodológicas e/ou proposições de modelos sem teste empírico, mesmo que estivessem inclusos no campo da Psicologia Organizacional e do Trabalho.

2 Fundação Coordenação de Aperfeiçoamento de Pessoal de Nível Superior.

3 Associação Nacional de Pesquisa e Pós-Graduação em Psicologia.

4 Universidade Federal do Rio Grande do Norte.

5 Universidade Federal da Paraíba.

6 Brasileiros que nunca estudaram ou que estudaram até um ano.

7 O IBGE ainda não disponibilizou informação equivalente referente ao último Censo.

8 Estimativas da Central Geral dos Trabalhadores, em 1993, indicam um índice de analfabetismo entre os operários da construção civil em torno de $70 \%$, incluindo os chamados analfabetos funcionais.

Livia de Oliveira Borges, doutora em Psicologia pelo Instituto de Psicologia da UNB, com estágio na Facultad de Ciencias Políticas y Sociales da Universidad Complutense de Madrid, é professora do Departamento de Psicologia da Universidade Federal do Rio Grande do Norte. Endereço para correspondência: Rua Prof. Luiz Carlos Teixeira, 10, Lagoa Nova, Natal, RN, 59075-130. Tel.: (84) 2344226. E-mail: liviab@ digi.com.br.

José Q. Pinheiro, doutor em Psicologia Ambiental pela Universidade do Arizona, Tucson (EUA), é professor do Departamento de Psicologia da Universidade Federal do Rio Grande do Norte. Endereço para correspondência: Caixa Postal 1507, Natal, RN, 59078-970. Telefax: (84) 215-3589. E-mail: pinheiro@cchla.ufrn.br. 